\title{
Chlorinated Imidazole Complexes as Potent Antifungal Agents
}

\author{
${ }^{1}$ Duru I.A., ${ }^{2}$ Ngochindo R.I., ${ }^{3}$ Duru C.E., ${ }^{1}$ Ogukwe C.E. and ${ }^{2}$ Orji I. \\ ${ }^{I}$ Department of Chemistry, Federal University of Technology Owerri, Imo State Nigeria \\ ${ }^{2}$ Department of Chemistry, University of Portharcourt, River State, Nigeria \\ ${ }^{3}$ Department of Chemistry, Alvan Ikoku Federal College of Education Owerri, Imo State Nigeria
}

\begin{abstract}
DCI) was synthesized and characterized using spectroscopic methods. The compound and its complexes did not show any significant antibacterial activity against Streptococcus pyogenes, Staphylococcus aureus, Pseudomonas aeruginosa and Proteus spp, when compared with the good activity shown by imidazole which is its precursor compound. Imidazole however showed complete inactivity against the fungi strains Aspergillus spp, Candida spp and Trichophyton spp. These fungi were very sensitive to DCI with further sensitivity shown to the $\mathrm{Cr}^{3+}$ and $\mathrm{Co}^{2+}$ complexes of the compound. These two complexes of DCI were also more active than the standard antifungal drug ketoconazole in inhibiting the growth of these fungi making them very potent compounds in the search for antifungal agents.
\end{abstract}

Keywords: 4,5-dichloroimidazole, Antibacterial activity, Antifungal agents, Imidazole, Ketoconazole

\section{Introduction}

Imidazole is an aromatic heterocyclic organic compound with the formula $\mathrm{C}_{3} \mathrm{H}_{4} \mathrm{~N}_{2}$ and is classified as an alkaloid. The compound is aromatic due to the presence of a sextet of $\pi$-electrons, consisting of a pair of electrons from the protonated nitrogen atom and one from each of the remaining four atoms of the ring. It exists in two equivalent tautomeric forms, $1 \mathrm{H}$-imidazole and $3 \mathrm{H}$-imidazole, because the hydrogen atom can be located on either of the two nitrogen atoms. Its ring system is present in important biological building blocks, and many drugs contain an imidazole ring [1-5].

The development of antifungal agents has been very slow compared to the antibacterial ones. This can be attributed to the fact that bacteria are prokaryotic and hence offer numerous structural and metabolic targets that differ from those of human host. On the other hand, fungi are eukaryotes and consequently most agents toxic to fungi are also toxic to the host. Also because they are multicellular and more difficult to quantify than the bacteria, a lot of setbacks are experienced in experiments designed to evaluate their in vitro and in vivo properties. Despite these limitations, the search for new antifungal agents is still on-going.

Chlorine may be essential for a compound to have any biological activity. Amongst the known chlorinated, biologically-active ingredients used in medicine and agriculture, there is a group of compounds that owe their biological activity to the presence of all, or specific individual chlorine atoms attached to the molecule. About $1.5 \%$ of all structurally known, natural compounds contain chlorine bound to a carbon atom. The chlorine substituent is essential for significant biological activity in a number of natural products such as the antibiotics clindamycin [6], vancomycin [7], chlo-ramphenicol and griseofulvin [8], the antitumour compounds cryptophycin [9], rebeccamycin [10], clavulon [11], neopyrolomycin [12] and astin A [13]. The weak fungicidal activity of benzylalcohol is improved by a factor of a hundred [14] by increasing the number of chlorine atoms from zero or one chlorine atom, to three chlorine atoms.

Some inactive biological ligands developed good antimicrobial properties upon chelation with transition metals [15-16]. This interaction may enhance or suppress their antimicrobial activity but usually in many cases, the pharmacological activity of antibiotics, after complexation with metals, is enhanced as compared to that of the free ligands [17].

The antimicrobial studies of chlorinated organic compounds, some with imidazole nucleus abound in literature. However, the direct application of chlorinated imidazole and its complexes as antimicrobial agents are scarce. 4,5-dichloroimidazole (DCI) and its complexes would be synthesized in this study and their antimicrobial activities tested on some selected bacteria and fungi strains.

\subsection{Synthesis of 4,5-dichloroimidazole}

\section{Methodology}

4,5-trichloroimidazole was synthesized using the procedure according to Lutz and Delorenzo [18], with a little modification. Imidazole ( $1.5 \mathrm{~g}, 0.02$ mole) was added to $1.16 \mathrm{~g}$ of sodium hypochlorite ("Chlorox" 8.25 $\mathrm{w} / \mathrm{v}, 14 \mathrm{ml}$ ) with stirring. The solution turned yellow then orange, and the temperature rose to $42{ }^{\circ} \mathrm{C}$. After 5 minutes the $\mathrm{pH}$ was adjusted to 4.0 with concentrated $\mathrm{HCl}$. The light orange precipitate formed was collected, washed with distilled water and dried. The product was further recrystallized from water. 


\subsection{Preparation of 4,5-trichloroimidazole Metal Complexes}

All the complexes were prepared using the same procedure. 1 mmole of each hydrated metal salt were dissolved in $2 \mathrm{ml}$ of distilled water and added a drop at a time with continuous stirring to 2 mmoles of the DCI dissolved in $10 \mathrm{ml}$ of acetone. The mixture was stirred at room temperature for half an hour and allowed to stand. The crystals formed were filtered through sintered glass crucible, washed with cold water and dried under vacuum at $50^{\circ} \mathrm{C}$. The products were recrystallized with redistilled ethanol.

\subsection{Characterization of Products}

DCI and its transition metal complexes were characterized by FT-IR, mass spectral and nuclear magnetic resonance data.

FT-IR spectra were obtained using $\mathrm{KBr}$ discs and Nujol mull techniques on IR Spectrophotometer FTIR 8400 S Shimadzu in the $4000-450 \mathrm{~cm}^{-1}$ range. The important IR bands indicating the formation of the compound and complexes were studied.

Mass spectra were obtained from Shimadzu LCMS-2010EV Liquid Chromatography Mass Spectrometer, ESI.

NMR spectra were recorded in DMSO- $\mathrm{d}_{6}$, on a Varian 400-MR Magnetic Resonance Spectrometer.

\subsection{Studies of Antimicrobial Activity of Products \\ 2.4.1 Collection of Microbial Cultures}

Pure clinical isolates of Streptococcus pyogenes, Staphylococcus aureus, Pseudomonas aeruginosa, Proteus spp, Aspergillus spp, Candida spp and Trichophyton spp were collected from the Microbiology Department of the Federal Medical Center Owerri, Imo State Nigeria. A microbial loop was used to remove a colony of each organism from the pure culture and transferred into liquid broth (Nutrient broth) and incubated for 24 hours at $37^{\circ} \mathrm{C}$. These were maintained in sterile conditions.

\subsubsection{Determination of antimicrobial Activity of Ligand and its Complexes}

Paper disc diffusion method was used for the determination of the antibacterial activity of the ligand and its complexes.

The equipments, petri dishes, flasks, pipettes, tweezers, forceps and wire loops were first thoroughly washed with detergent and distilled water then sterilized by dry heat method in a hot air oven at $200{ }^{\circ} \mathrm{C}$ for 2 hours. The sterilized equipments were kept under laminar air flow where subsequent procedure was completed. Other materials and media were sterilized by autoclaving at $120^{\circ} \mathrm{C}$ for 20 minutes.

Solutions of the DCI and its complexes containing $200 \mathrm{mg} / \mathrm{ml}$ of each compound were prepared and absorbed on the paper disc prepared from Whatman filter papers $(3 \mathrm{~mm}$ size) with the help of a micropipette. The solutions were then serial diluted to obtain $100 \mathrm{mg} / \mathrm{ml}, 50 \mathrm{mg} / \mathrm{ml}$ and $25 \mathrm{mg} / \mathrm{ml}$ concentrations and each concentration applied on separate filter paper discs. These discs were left in an incubator for 24 hours at $37^{\circ} \mathrm{C}$. Antimicrobial activity of DCI and its metal complexes were determined separately. A sterilized forceps was used for the application of the paper discs with different concentrations of the prepared solutions on the already incubated agar plates. When the discs were applied, they were incubated at $37^{\circ} \mathrm{C}$ for 24 hours. The diameter of inhibition zone was measured.

\section{Results And Discussion}

The product obtained had a mass of $2.3 \mathrm{~g}$, which is equivalent to a yield of $49 \%$ with a melting point ranging between $180-181{ }^{\circ} \mathrm{C}$.

The mass spectrum of DCI gave a molecular ion peak corresponding to the formula $\mathrm{C}_{3} \mathrm{H}_{2} \mathrm{~N}_{2} \mathrm{Cl}_{2}\left(\mathrm{M}^{+}=\right.$ 136.9) which corresponds to the mass of the compound.

The ${ }^{1} \mathrm{H}-\mathrm{NMR}$ gave peaks at $7.704 \mathrm{ppm}$ and $13.307 \mathrm{ppm}$ and were assigned to $\mathrm{C} 2$ hydrogen and $\mathrm{N}-\mathrm{H}$ hydrogen respectively, for a 4,5 -substituted imidazole. A peak at $134.165 \mathrm{ppm}$ on the ${ }^{13} \mathrm{C}$-NMR was assigned to the unsubstituted $\mathrm{C} 2$ in the imidazole.

The colours of the products and their characteristic bands in the IR spectrum are shown in Table 1.

Table 1: Colour and IR data of DCI and its coordination compounds

\begin{tabular}{|c|c|c|c|c|c|c|}
\hline Compound & Colour & $v(\mathrm{~N}-\mathrm{H}) \mathrm{cm}^{-1}$ & $v(\mathrm{C}-\mathrm{Cl}) \mathrm{cm}^{-1}$ & $\mathrm{v}(\mathrm{C}=\mathrm{N}) \mathrm{cm}^{-1}$ & $v(C-N) \mathrm{cm}^{-1}$ & $v(C=C) \mathrm{cm}^{-1}$ \\
\hline DCI & Orange & $3500 \mathrm{vw}$ & $641 \mathrm{~s}$ & $1650 \mathrm{vW}$ & $1315 \mathrm{~s}$ & $1558 \mathrm{~m}$ \\
\hline [Co(DCI)] & Purple & $3414 \mathrm{~m}$ & $640 \mathrm{~m}$ & $1648 \mathrm{~m}$ & $1314 \mathrm{~m}$ & $1558 \mathrm{w}$ \\
\hline [Cr(DCI)] & $\begin{array}{l}\text { Dirty } \\
\text { green }\end{array}$ & $3429 \mathrm{~s}$ & $640 \mathrm{~m}$ & $1636 \mathrm{w}$ & 1314 s & $1575 \mathrm{vw}$ \\
\hline [Cu(DCI)] & $\begin{array}{l}\text { Deep } \\
\text { green }\end{array}$ & $3461 \mathrm{br}$ & $636 \mathrm{~m}$ & $1636 \mathrm{w}$ & $1315 \mathrm{~s}$ & $1558 \mathrm{~s}$ \\
\hline [Fe(DCI)] & Brown & $3410 \mathrm{~m}$ & $638 w$ & $1648 \mathrm{~m}$ & $1314 \mathrm{~s}$ & $1571 \mathrm{w}$ \\
\hline
\end{tabular}


$\mathrm{vw}=$ very weak; $\mathbf{m}=$ medium; $\mathbf{w}=$ weak; $\mathbf{s}=$ strong; $\mathbf{b r}=$ broad $; \mathbf{v}=$ variable intensity

The frequencies $3500 \mathrm{~cm}^{-1}, 641 \mathrm{~cm}^{-1}, 1650 \mathrm{~cm}^{-1}, 1315 \mathrm{~cm}^{-1}$ and $1558 \mathrm{~cm}^{-1}$ observed in the scan were assigned to $\mathrm{N}-\mathrm{H}$ for secondary amine, $\mathrm{C}-\mathrm{Cl}, \mathrm{C}=\mathrm{N}$ for cyclic $\alpha, \beta$-unsaturation, $\mathrm{C}-\mathrm{N}$ for aromatic secondary amine and $\mathrm{C}=\mathrm{C}$ for pyrroles respectively and are the main functional groups in DCI. The marked difference in the absorbance value of the DCI ligand at $3500 \mathrm{~cm}^{-1}(\mathrm{~N}-\mathrm{H})$ when compared with those of its complexes is an indication that the $\mathrm{N}-\mathrm{H}$ in the imidazole ring may be involved in the complexation.

The activities of DCI and its $\mathrm{Co}^{2+}, \mathrm{Cr}^{3+}, \mathrm{Cu}^{2+}$ and $\mathrm{Fe}^{2+}$ complexes on Streptococcus pyogenes, Staphylococcus aureus, Pseudomonas aeruginosa, Proteus spp, Aspergillus spp, Candida spp and Trichophyton spp are shown in Table 2 and Table 3.

Table 2: Activity of 4,5-dichloroimidazole (DCI) and its complexes against some bacteria strains

\begin{tabular}{|c|c|c|c|c|c|}
\hline \multirow[t]{2}{*}{ Samples } & \multirow{2}{*}{$\begin{array}{l}\text { Concentrations } \\
(\mathrm{mg} / \mathrm{ml})\end{array}$} & \multicolumn{3}{|c|}{ Diameter of Zone of Inhibition (mm) } & \multirow[b]{2}{*}{ Proteus spp } \\
\hline & & $\begin{array}{l}\text { Streptococcus } \\
\text { pyogenes }\end{array}$ & $\begin{array}{l}\text { Pseudomonas } \\
\text { aeruginosa }\end{array}$ & Staphylococcus aureus & \\
\hline IMIDAZ & 200 & 20 & 26 & 24 & 18 \\
\hline \multirow[t]{3}{*}{ OLE } & 100 & 14 & 20 & 20 & 12 \\
\hline & $\mathbf{5 0}$ & 8 & 12 & 12 & 8 \\
\hline & 25 & 2 & 6 & 4 & 2 \\
\hline \multirow{4}{*}{ DCI } & 200 & 16 & 20 & 16 & 10 \\
\hline & 100 & 10 & 20 & 14 & 8 \\
\hline & 50 & 6 & 10 & 8 & 6 \\
\hline & 25 & 4 & 4 & 6 & 2 \\
\hline \multirow{4}{*}{ DCI-Co } & 200 & 20 & 16 & 18 & 22 \\
\hline & 100 & 16 & 14 & 12 & 16 \\
\hline & 50 & 10 & 10 & 8 & 10 \\
\hline & 25 & 6 & 6 & 6 & 8 \\
\hline \multirow{4}{*}{ DCI-Cr } & 200 & 24 & 20 & 20 & 18 \\
\hline & 100 & 16 & 12 & 14 & 14 \\
\hline & 50 & 10 & 6 & 10 & 8 \\
\hline & 25 & 8 & 4 & 8 & 6 \\
\hline \multirow{4}{*}{ DCI-Cu } & 200 & 10 & 16 & 10 & 10 \\
\hline & 100 & 4 & 12 & 8 & 6 \\
\hline & 50 & 2 & 8 & 4 & 4 \\
\hline & 25 & - & 4 & - & - \\
\hline \multirow{4}{*}{ DCI-Fe } & 200 & 12 & 14 & 16 & 22 \\
\hline & 100 & 10 & 14 & 12 & 18 \\
\hline & 50 & 8 & 10 & 6 & 14 \\
\hline & 25 & 4 & 6 & 4 & 10 \\
\hline $\begin{array}{l}\text { Levofloxa } \\
\text { cin }\end{array}$ & 2 & 14 & 14 & 10 & 8 \\
\hline
\end{tabular}

Table 3: Activity of 4, 5-dichloroimidazole (DCI) and its complexes against some fungi strains

\begin{tabular}{|c|c|c|c|c|}
\hline \multirow[t]{2}{*}{ Samples } & \multirow{2}{*}{$\begin{array}{l}\text { Concentrations } \\
(\mathrm{mg} / \mathrm{ml})\end{array}$} & \multicolumn{3}{|c|}{ Diameter of Zone of Inhibition (mm) } \\
\hline & & Aspergillus spp & Candida spp & Trichophyton spp \\
\hline \multirow{4}{*}{ IMIDAZOLE } & 200 & - & - & - \\
\hline & 100 & - & - & - \\
\hline & 50 & - & - & - \\
\hline & 25 & - & - & - \\
\hline \multirow{4}{*}{ DCI } & 200 & 10 & 16 & 16 \\
\hline & 100 & 6 & 14 & 12 \\
\hline & 50 & 4 & 10 & 8 \\
\hline & 25 & - & 4 & 6 \\
\hline \multirow{4}{*}{ DCI-Co } & 200 & 20 & 22 & 18 \\
\hline & 100 & 14 & 16 & 10 \\
\hline & 50 & 10 & 14 & 8 \\
\hline & 25 & 8 & 10 & 4 \\
\hline \multirow{4}{*}{ DCI-Cr } & 200 & 24 & 20 & 20 \\
\hline & 100 & 16 & 16 & 14 \\
\hline & 50 & 12 & 10 & 10 \\
\hline & 25 & 8 & 6 & 8 \\
\hline \multirow{4}{*}{ DCI-Cu } & 200 & 14 & 16 & 14 \\
\hline & 100 & 10 & 14 & 10 \\
\hline & 50 & 6 & 8 & 8 \\
\hline & 25 & 2 & 4 & 6 \\
\hline \multirow{4}{*}{ DCI-Fe } & 200 & 10 & 14 & 16 \\
\hline & 100 & 4 & 10 & 12 \\
\hline & 50 & - & 8 & 10 \\
\hline & 25 & - & 4 & 6 \\
\hline Ketoconazole & 200 & - & - & 2 \\
\hline
\end{tabular}


From table 1, the imidazole compound gave very good activity against the different bacteria strains studied, with its activity at the concentrations between $100-50 \mathrm{mg} / \mathrm{ml}$ close to the standard antibiotics levofloxacin. The halogenated derivative DCI generally did not give any significant change in the activity relative to its precursor compound. What was observed was a slight reduction in sensitivity of the imidazole by its chlorination to the 4,5-derivative. This is a clear indication that the dichlorination of imidazole at the 4,5positions does not enhance its antibacterial property, but rather what is obtained is a reduction in sensitivity by the bacteria with particular reference to the strains under study in this work.

Complexation with transition metals also did not improve the bactericidal activity of the DCI. Marginal increases in sensitivity relative to the imidazole were observed in the copper and iron DCI complexes against Proteus spp. The chromium DCI complex also gave a relatively fair improvement in activity against Streptococcus pyogenes.

Imidazole however did not give any activity against the three fungi strains used in this study, showing that this compound in its form is not a likely antifungal agent. All the fungi strains showed good sensitivity to its 4,5-chlorinated derivative. This is an indication that the DCI is a much better antifungal compound than the imidazole. The copper and iron complexes of DCI showed antifungal activities similar to the uncomplexed DCI which suggests that the complexes of these metals do not change the antifungal property of DCI. Very good activities were observed with the chromium and cobalt complexes of DCI with the fungi showing significant sensitivity to these complexes at low concentration of $25 \mathrm{mg} / \mathrm{ml}$. The activities of these two complexes were also better than the standard antifungal drug ketoconazole.

\section{Conclusion}

This study has show that imidazole is an antibacterial compound and this property is not changed by its chlorination at the 4,5-positions. Complexing with the transition metals used in this study does not also give a significant improvement in the antibacterial activity of the 4,5-chlorinated compound. The apparent inactivity of imidazole on fungi strains however was reversed by chlorination at its 4,5-positions, giving good activity on the studied strains of fungi with further improvement in the observed sensitivity by the organisms when complexed with chromium and copper salts.

\section{Acknowledgements}

We are very grateful to the Education Trust Fund of Nigeria, for their financial assistance. Our gratitude also goes to Asclepia Outsourcing Solutions Destelbergen Belgium, for providing spectroscopic characterization.

\section{References}

[1] A.R. Katritzky and C.W. Rees, Comprehensive Heterocyclic Chemistry (Pergamon Press, Oxford, 1985)

[2] M.R. Grimmett. Imidazole and Benzimidazole Synthesis (Academic Press, 1997).

[3] E.G. Brown, Ring Nitrogen and Key Biomolecules (Academic Press, 1998).

[4] A.F. Pozharskii, Heterocycles in Life and Society (John Wiley \& Sons, 1997)

[5] T.L. Gilchrist, Heterocyclic Chemistry (The Bath Press 1985).

[6] R.D. Birkenmeyer and F. Kagan, Lincomycin.XI. synthesis and structure of clindamycin. A potent antibacterial agent, J. Med. Chem., 13, 1970, 616

[7] C. Harris, R. Kannan, H. Kopecka and T. M. Harris, the role of chlorine substituents in the antibiotic vancomycin: preparation and characterization of mono- and didechlorovancomycin, J. Am. Chem. Soc., 107, 1985, 6652-6658.

[8] R. Crosse, R. McWilliams and A. Rhodes, Some relationships between chemical structure and antifungal effects of griseofulvin analogues, J. Gen. Microbiol., 34, 1964, 51-65.

[9] T. Golakoti, J. Ogino, C. E. Heltzel, L. Le Husabo, C. M. Graig, L. K. Larsen, G. Patterson, R. E. Moore and S. L. Mooberry, Structure determination, conformational analysis, chemical stability studies and antitumor evaluation of the cryptophycins. Isolation of 18 new analogs fron Nostoc sp strain GSV 224, J. Am. Chem. Soc., 117, 1995, 12030-12049.

[10] J.A. Bush, B.H. Long, J.J. Catino and W.T. Bradner, Production and biological activity of rebeccamycin, a novel antitumor agent, J. Antibiot., 40(5), 1987, 668-678.

[11] Y. Yamada and I. Nagoka, Synthesis of a halogenated clavulone analog, Tetrahedron Lett., 26, 1985, 5053-5056.

[12] K. Tatsuda and M. Itoh, Synthesis and biological evaluation of neopyrrolomycin analogs, J. Antibiot., 47, $1994,262-265$.

[13] H. Morita, J. Nagashima, Y, Uchiumi, O. Kurobi, K. Takeda and H. Itokawa, Cyclic peptides from higher plants. XXVIII. Antitumor activity and hepatic microsomal biotransformation of cyclic pentapeptides, Astins from Aster tataricus, Chem. Pharm. Bull., 44, 1996, 1026-1032.

[14] C. Hansch, E.J. Lien, Structure-activity relationship in antifungal agents, J. Med. Chem., 14, 1971, 653-670.

[15] M. N. Hughes, The Inorganic Chemistry of Biological Processes, (2 Ed., Wiley, New York, 1981).

[16] M. S. Iqbal, A. R. Ahmad, M. Sabir and S. M. Asad, Preparation, characterization and biological evaluation of copper(II) and zinc(II) complexes with cephalexin, J. Pharm. Pharmacol., 15(4), 1999, 371-375.

[17] N. Nawar and N. M. Hosny, Synthesis, spectral and antimicrobial activity studies of o-aminoacetophenone ohydroxybenzoylhydrazone, Transition Metal Chemistry, 25, 2000, 1-8.

[18] Lutz A.W. and Delorenzo S., Novel halogenated imidazoles. Chloroimidazoles, 4, 400-401. 